\title{
Immediate shock, passive avoidance, and potentiated startle: Implications for the unconditioned response to shock
}

\author{
M. J. KIERNAN \\ Charles Sturt University, Mitchell, Bathurst, New South Wales, Australia \\ and \\ R. F. WESTBROOK and J. CRANNEY \\ University of New South Wales, Kensington, New South Wales, Australia
}

\begin{abstract}
Three experiments were performed to study the immediate-shock freezing deficit, a deficit in freezing in rats that results when electric shock is delivered immediately upon exposure to a novel context. This deficit was accompanied by failures to detect evidence of passive avoidance (Experiment 1) or potentiation of the auditory startle response (Experiment 2). The deficit in freezing was attenuated by preexposure to the shocked context (Experiment 3 ). The results support the view that fear-related behaviors are activated by signals for shock rather than by shock itself. They also suggest that the immediate-shock freezing deficit is due to a failure to process the to-be-conditioned contextual cues (Fanselow, 1986a, 1990).
\end{abstract}

Rats placed in a distinctive context and given a brief electric shock show a biphasic pattern of responding in the postshock period, consisting of an initial activity burst followed by prolonged immobility or freezing (Blanchard \& Blanchard, 1969; Fanselow, 1980, 1982, 1984). Although the duration of the activity burst is determined by the intensity of the shock (Fanselow, 1982), postshock freezing is highly sensitive to an animal's experience with the conditioning context (Fanselow, 1990; Kiernan \& Westbrook, 1993; Westbrook, Good, \& Kiernan, in press). Of particular significance for the present experiments is the finding that a context in which shock is delivered immediately upon placement of the rat into the apparatus fails to elicit freezing either in the postshock period (Blanchard, Fukunaga, \& Blanchard, 1976) or during subsequent exposure to that context (Fanselow, 1986a). This failure in conditioning is termed the immediate-shock freezing deficit (Fanselow, 1986a, 1990).

Fanselow $(1980,1984)$ has argued that postshock freezing is a response to shock-associated cues, rather than a response elicited by the shock itself. From this

This research was supported by an Australian Post-Graduate Scholarship to the first author, and by Australian Research Council Grants to the second and third authors. The experiments were conducted in the School of Psychology, University of New South Wales, and were approved by the University's Committee for the Use of Animals in Research and Teaching. Portions of this research were presented at the 17th Experimental Psychology Conference, Canberra, Australia, in July of 1990. Correspondence should be addressed to M. J. Kiernan, School of Social Science and Liberal Studies, Charles Sturt University, Mitchell, Bathurst, NSW 2795, Australia.

-Accepted by previous editor, Vincent M. LoLordo view, the context functions as a conditional stimulus (CS) in the absence of a discrete signal for shock. However, the context consists of a complex set of distinctive features that must be sampled and encoded to form a configural representation consisting of a network of associations among individual elements. This process of feature integration takes time. Thus, the ability of a context to function as a CS and, hence, its ability to elicit postshock freezing increases with the extent to which conditions allow processing of contextual features prior to shock delivery. Failure to obtain freezing with immediate shock is an associative deficit resulting from insufficient processing of the context into a unitized CS. Conditioned freezing can be increased under these circumstances, however, by preexposing rats to the conditioning context or by increasing the time interval from apparatus placement to the delivery of the first shock (Fanselow, 1990; Kiernan \& Westbrook, 1993; Westbrook et al., in press).

The failure of immediate shock to condition freezing is consistent with the perceptual-defensive-recuperative (PDR) model, which asserts that painful stimuli do not unconditionally elicit fear-motivated behavior (Bolles \& Fanselow, 1980; Fanselow, 1986a, 1986b). This model assumes that pain-related recuperative behavior and fear-related defensive behavior (e.g., freezing) are under the control of functionally and anatomically distinct motivational systems. The recuperative (pain) system, but not the defensive (fear) system, is activated by painful stimuli. Pain influences fear only indirectly through the processes of Pavlovian conditioning so that cues associated with a painful stimulus (e.g., shock), but not that stimulus itself, activate the defensive system. 
Rather than view the activity burst as a response to shock, and the subsequent freezing as a response to shock-associated contextual cues, Wagner and Brandon (1989) have argued that this biphasic pattern constitutes the unconditioned response (UR) to a shock unconditioned stimulus (US). This argument is derived from Wagner's (1981) sometimes-opponent-process (SOP) model, which assumes that processing of the shock stimulus decays gradually from a primary state of activation (A1), through a secondary level of activation (A2), to an inactive state (I) in a long-term memory (LTM) store. The initial activity burst is provoked by the representation of shock in $\mathrm{A} 1$, with secondary freezing resulting from the shock representation in $\mathrm{A} 2$.

The immediate-shock deficit apparently conflicts with the SOP explanation of postshock freezing, since this deficit suggests that freezing is not an inevitable consequence of presenting a shock US. However, Wagner and Brandon's (1989) affective extension of SOP (AESOP) also maintains that shock generates a pattern of affective dynamics during its processing in $\mathrm{A} 1$ and $\mathrm{A} 2$, such that fear is a consequence of processing the painful US in A2. Presumably, this fear state can be indexed by a range of behaviors, including freezing. Thus, the AESOP model might accommodate the immediate-shock freezing deficit by arguing that freezing imperfectly indexes the fear state that constitutes the second component of the affective processing accorded a shock US.

In Experiments 1 and 2, we investigated the effect of immediate shock on three behavioral indexes of fear. If the immediate-shock freezing deficit is due to the inability of immediate shock to activate a defense motivational system, then the response deficit that occurs with immediate shock also should characterize other fear indexes. In this regard, we examined step-down passive avoidance (Westbrook, Greeley, Nabke, \& Swinbourne, 1991) and fear-potentiated startle (Davis, 1989) following immediate- or delayed-shock conditioning procedures. In Experiment 3, we examined the hypothesis that the mechanism underlying the immediate-shock freezing deficit is a disruption in processing the conditioning context at the time of shock delivery.

\section{EXPERIMENT 1}

In Experiment 1, we used a step-down passive avoidance test (Westbrook et al., 1991) following a single trial conditioning procedure to examine whether delayed, but not immediate, shock is capable of conditioning fear to apparatus cues. Rats were placed into the test apparatus on Day 1 and received a single shock either immediately or after a 60 -sec delay. A control group did not receive shock. Twenty-four hours later, the rats were returned to the apparatus, where they were placed onto a platform and their latency to step down onto the (unelectrified) grid floor was recorded. If immediate shock fails to condition fear to apparatus cues, then the immediate-shock group should not differ in their step-down latencies from no-shock controls. In contrast, rats shocked after a delay should show significantly longer step-down latencies than do rats in the control group.

We also manipulated the length of the postshock period during which rats were left in the apparatus on the conditioning day, in order to evaluate the hypothesis that the immediate-shock freezing deficit is a result of incompatibility between freezing and a search for potential escape routes (Blanchard et al., 1976). Freezing may fail to emerge in the immediate-shock condition because rats have yet to learn that escape from the chamber is not possible. Thus, half of the rats in each shock condition remained in the apparatus for $10 \mathrm{sec}$ following shock; the other rats in each condition stayed in the apparatus for $120 \mathrm{sec}$. If immediate shock fails to engender freezing on the conditioning day because rats are searching for escape routes, then a rat's certainty about the absence of such routes should increase with the opportunity for postshock exploration. In the present design, one might expect that the certainty that escape routes do not exist should decrease the motivation to leave the platform in the 120 -sec groups relative to the 10 -sec groups and thus increase step-down latencies.

\section{Method}

Subjects. Forty-eight experimentally naive, male Wistar rats $(350-400 \mathrm{~g})$ were obtained from the colony of specificpathogen-free rats maintained by the University of New South Wales. The rats were housed in groups of 8 in plastic boxes $(65$ $\times 40 \times 32 \mathrm{~cm}$ ) in a colony room maintained on a 12:12-h light:dark cycle. Food and water were continuously available in the home cages.

Apparatus. Conditioning and testing occurred in two chambers $(20 \times 23 \times 21 \mathrm{~cm})$. Each chamber consisted of Perspex front and rear walls, a hinged Perspex lid, and stainless steel end walls. The floor consisted of stainless steel rods, $2 \mathrm{~mm}$ in diameter, spaced $1 \mathrm{~cm}$ apart center to center. The two chambers were placed in separate compartments of a wooden cabinet. The door of each compartment was kept open to permit observation of the rat. The chambers were cleaned with a solution of $0.5 \mathrm{ml}$ acetic acid per $100 \mathrm{ml}$ of tap water (Fanselow, 1980) and sawdust in the trays $5 \mathrm{~cm}$ below the chambers was replaced before each rat was placed in a chamber. Unscrambled ac $50-\mathrm{Hz}$ shock from a constant-current generator (constructed at the University of New South Wales) was delivered to the floor of each chamber. The current available to each floor was based on that supplied to a $300-\mathrm{g}$ rat and adjusted by reference to an inline milliamp meter. On the test day, a quarter circle wooden platform ( $8 \mathrm{~cm}$ high, $12 \mathrm{~cm}$ radius) was placed into each chamber. The straight edges sat flush against the corner walls of the chamber, and the platform occupied a total of $23.4 \%$ of the floor.

Procedure. We handled the rats for 2 min on each of 4 consecutive days and randomly allocated rats to groups. On the conditioning day, we placed rats in the chambers and delivered shock ( $1 \mathrm{sec}, 0.9 \mathrm{~mA}$ ) either immediately (Groups IMM) or after a delay of $60 \mathrm{sec}$ (Groups DEL). Rats in each shock condition were removed from the chambers either $10 \mathrm{sec}$ (Groups IMM10 and DEL10) or $120 \mathrm{sec}$ (Groups IMM120 and DEL120) after shock ( $n=8$ per group). We also exposed control rats (Groups CON) to the chambers for $10,70,120$, or $180 \sec (n=4$ per group), but delivered no shock. Behavioral freezing was sampled at 2 -sec intervals for each rat in Groups IMM120, DEL120, CON120, and CON 180 during the final 120 -sec period of the conditioning ses- 
sion. Freezing was defined as the absence of movement of body or vibrissae, except for movement associated with respiration (Fanselow, 1980).

Twenty-four hours later, we returned all the rats to the chambers in which the wooden platforms were now in place. The latency to step down onto the floor with all four paws was recorded. Rats that failed to step down within $8 \mathrm{~min}$ were removed and given a stepdown score of $480 \mathrm{sec}$.

To determine the occurrence of freezing responses in this and subsequent experiments, rats were video recorded and the tapes scored by two observers. Pearson correlation coefficients exceeded 9. Statistical analyses were carried out with a Hays (1972) procedure to test orthogonal planned contrasts with a decisionwise error rate of $\alpha=.05$.

\section{Results}

Mean percent freezing during the final $120 \mathrm{sec}$ of the conditioning session for rats receiving immediate shock (IMM120), delay shock (DEL120), and no shock (CON120 combined with CON180) are shown in the left portion of Figure 1. An immediate-shock freezing deficit was evident on the day of conditioning: Whereas Group IMM120 and the no-shock control groups displayed little or no freezing, rats shocked $60 \mathrm{sec}$ after exposure to the chamber showed considerable levels of freezing. Statistical analysis confirmed that there was significantly more freezing among rats in Group DEL120 than in the other groups $[F(1,21)=270.086, p<.001]$. Moreover, freezing in Group IMM120 did not differ significantly from that in no-shock controls $(F<1.0)$.

There were no systematic differences in step-down latencies during testing among the no-shock control rats exposed to the chambers for 10 (range, $2.7-35 \mathrm{sec}$ ), 70 (range, 1.6-10.0 sec), 120 (range, 4.5-30.0 sec) and $180 \mathrm{sec}$ (range, $1.6-25.0 \mathrm{sec}$ ) on the previous conditioning day. Therefore, the results from these subgroups were combined into two groups (CON10 and CON120) to control for variations in time spent in the chamber after the delivery of shock by rats in the immediate and delay conditions.

Mean step-down latencies during the test day are shown in the right portion of Figure 1. Rats in the delayed-shock condition had significantly longer stepdown latencies than did other groups $[F(1,42)=$ $120.161, p<.001]$; however, rats in the immediateshock condition did not differ significantly from noshock controls $[F(1,42)=2.107, p>.1]$. Time spent in the chambers following shock on the conditioning day did not exert any differential effect on step-down latencies. Statistical analysis showed that step-down latencies did not differ significantly among rats removed from the context $10 \mathrm{sec}$ after shock and those removed $120 \mathrm{sec}$ after shock $(F<1.0)$. Further, postshock time did not interact significantly with shock condition (all $\left.F_{\mathrm{S}}<1.0\right)$.

\section{Discussion}

These results replicate the immediate-shock deficit (Blanchard et al., 1976; Fanselow, 1986a, 1990). Whereas rats shocked immediately upon exposure to the conditioning apparatus did not show any more freezing than did no-shock controls, rats shocked after a delay dis-

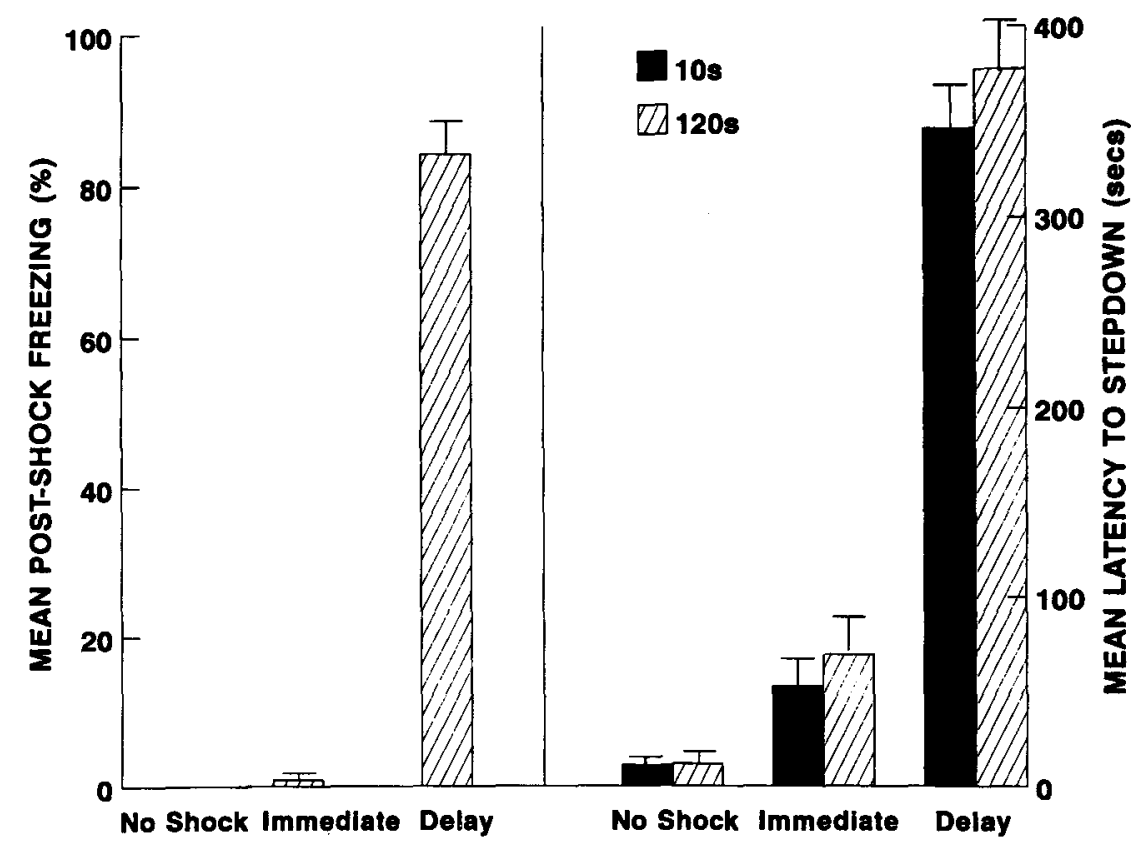

Figure 1. Mean percent freezing (left panel) for rats given immediate (IMM120), delayed (DEL120), or no shock (CON120 combined with CON180) and kept in that context for 120 sec. Mean step-down latencies (right panel) for rats receiving immediate or delayed shock on conditioning day and kept in that context for 10 or $120 \mathrm{sec}$. Control rats that spent 10 or $70 \mathrm{sec}$ in the context are termed $10 \mathrm{sec}$, and those that had remained there for 120 or $180 \mathrm{sec}$ are designated 120 sec. T-bars represent $S E M$ s. 
played substantial levels of freezing in the postshock period. These results are inconsistent with the view that freezing constitutes part of the rat's UR to a shock US (e.g., Wagner \& Brandon, 1989). The present results also show that variations in the time between exposure to the novel conditioning context and the occurrence of shock result in subsequent differences in step-down latencies onto a previously shocked floor. Rats shocked after a delay step down with long latencies, whereas rats shocked immediately subsequently step down with latencies that are indistinguishable from those of nonshocked rats. Viewed as an index of fear conditioning, the step-down latencies are consistent with the hypothesis that delayed but not immediate shock resulted in an association between the contextual cues and shock. In turn, the formation of this association among rats shocked after a delay, and the failure of this association among rats shocked immediately, can be invoked in a manner consistent with the PDR model to explain the differences between these rats in the levels of postshock freezing.

Step-down latencies were not affected by variations in the time spent in the postshock context. This finding suggests that the short step-down latencies of the immediateshock groups cannot be attributed to fear-mediated escape responses elicited because these rats had insufficient time on the day of conditioning to learn that the experimental context was inescapable.

\section{EXPERIMENT 2}

In Experiment 2, we used the fear-potentiated startle response to provide a further examination of the effect of shocking rats either immediately upon exposure to a novel context or after a delay. It is well documented that CSs paired with a shock US potentiate the acoustic startle response (Brown, Kalish, \& Farber, 1951; Davis \& Astrachan, 1978). Furthermore, the ability of such CSs to potentiate the startle response is highly correlated with the level of freezing provoked by those CSs (Leaton $\&$ Borszcz, 1985). Given the results of Experiment 1, this similarity between fear measures suggests that rats exposed to a novel context and shocked after a delay should display increased startle amplitudes to subsequently presented startle stimuli in comparison with noshock controls. Moreover, rats shocked immediately should display the same level of startle as do nonshocked rats, thus indexing the associative deficit taken to mediate the freezing and step-down performance observed in Experiment 1. Alternatively, if shock exerts a direct impact on the response to subsequently presented startle stimuli, then some potentiation of response amplitudes may be evident in an immediate-shock condition. Nonetheless, any potentiation caused by immediate shock should be less than that resulting from the combined effects of shock and conditioned fear in a delayedshock condition.

\section{Method}

Subjects. Thirty-nine experimentally naive male Wistar rats $(250-350 \mathrm{~g})$ were obtained from the same source and kept under the conditions described previously.

Apparatus. Two Plexiglas chambers $(20 \times 12 \times 12 \mathrm{~cm})$ were used to study startle amplitude. The floor consisted of stainless steel rods, $2 \mathrm{~mm}$ in diameter, spaced $1.25 \mathrm{~cm}$ apart center to center. Each chamber was suspended from a sheet of Plexiglas to which a piezoelectric film material had been laminated. An abrupt startle response caused the Plexiglas to flex slightly and created a voltage in the piezoelectric film that was linearly related to the force applied to the floor (Leitner \& Rosenberger, 1983). This voltage was fed into an analog-to-digital converter and recorded by a computer program designed to capture the highest positive peak within the first $100 \mathrm{msec}$. The two chambers were placed in separate compartments of a wooden cabinet. The cabinet was located in a sound-attenuating room. The compartments and the room were illuminated by red light. In each compartment, two Tandy piezoelectric speakers (Type 40-1379) wired in parallel were mounted $6 \mathrm{~cm}$ from either side of the chamber and were used to deliver startle-eliciting stimuli and background noise.

The startle-eliciting stimulus was a 105-dB SPL (re: $20 \mu \mathrm{Pa}$ ), 50-msec white noise burst. Continuous white noise (61-dB SPL re: $20 \mu \mathrm{Pa}$ ) was used to mask any extraneous auditory stimuli. The startle stimuli were superimposed on this background. The stimulus and background intensities were measured with a Brüel \& Kjaer sound level meter (Type 2235) with a microphone placed in a standard, central position in each chamber. All programming, timing, and startle stimulus presentations were computer controlled, and the acoustic stimuli were generated by a stimulus control module.

Scrambled shock was delivered by two constant-current shock generators (Grason-Stadler, Type E1064GS), located outside the experimental room and connected in series to alternate rods of each chamber's floor. The actual shock intensity was determined by recording the chamber output across a $1-\mathrm{k} \Omega$ resister with a digital storage oscilloscope (Leader, Type LBO-5825) and dividing the maximum peak-to-peak height by mean root square (cf. Davis, 1989). The mean shock intensity received by the immediate-shock group was $0.73 \mathrm{~mA}$ and that for the delay-shock group was $0.74 \mathrm{~mA}$.

Procedure. We handled the rats for 2 min on each of 3 consecutive days. On Day 4, startle responsiveness was determined by presenting the rats with five 110 -dB SPL (re: $20 \mu \mathrm{Pa}$ ) white noise startle stimuli on a variable time $30-\mathrm{sec}$ (range, $10-50 \mathrm{sec}$ ) schedule (cf. Davis, 1989). This baseline session occurred in a plastic cylinder (23 $\mathrm{cm}$ in diameter and $17 \mathrm{~cm}$ in depth) with a wooden lid and a central speaker. The cylinder stood on four upright supports upon a Plexiglas base. The amplitude of the startle response was measured via movements in a piezoelectric film laminated to the Plexiglas base in an identical way to that described for the experimental apparatus. On Day 5 , we weighed the rats and sorted them into triplets in which they were matched for startle amplitude and body weight. From each triplet, we assigned rats randomly to the three groups.

On Day 6, we placed the rats in the startle chambers and delivered a $0.8-\mathrm{mA}, 0.5-\mathrm{sec}$ shock either immediately $(n=13)$ or after a 60 -sec delay $(n=13)$. The first of 80 startle stimuli $(105 \mathrm{~dB})$ was presented $30 \mathrm{sec}$ after the shock on a fixed-time 30 -sec schedule. We arranged the same schedule of startle stimuli for the no-shock rats, initiating this schedule $30 \mathrm{sec}$ after placement in the apparatus for some rats $(n=6)$ and after $90 \mathrm{sec}$ for the other rats in this condition $(n=7)$.

Startle amplitudes were analyzed with a planned analysis of variance, with the family-wise-error rate maintained at $\alpha=.05$. A Bonferroni adjustment was used to test three nonorthogonal between- 


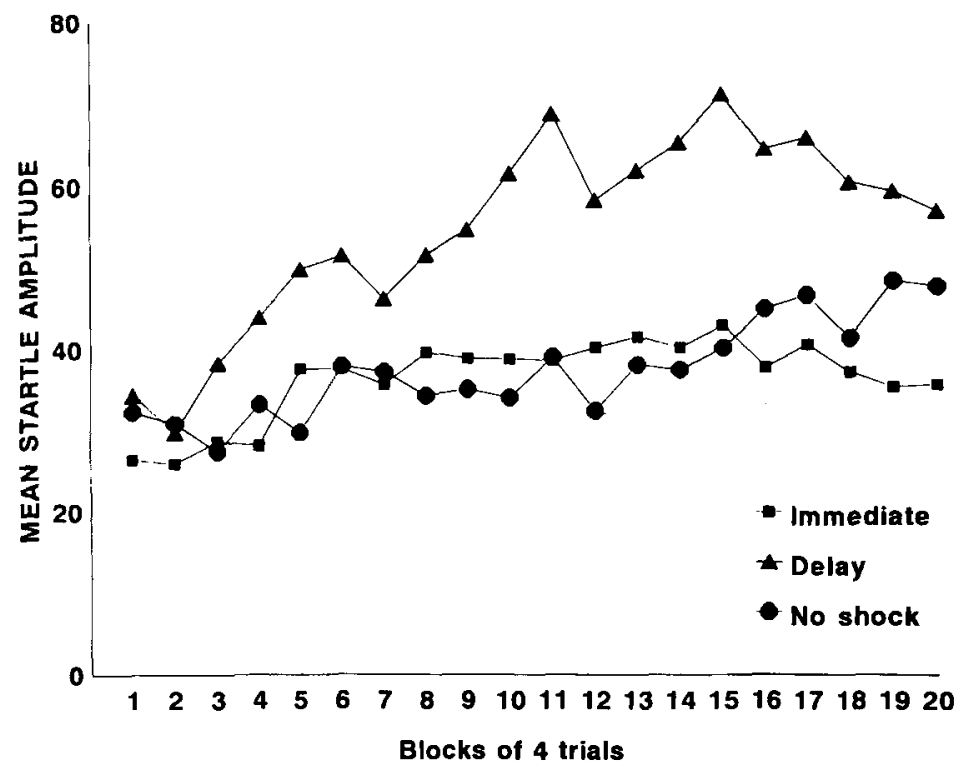

Figure 2. Mean startle amplitude in blocks of four stimulus presentations in Experiment 2. Startle stimuli were presented subsequent to immediate, delayed, or no shock.

group comparisons, as well as linear trend and interactions (cf. Miller, 1966). The critical $F$ for these contrasts was 6.4 and was obtained by setting $\alpha=.016$.

\section{Results}

A preliminary analysis revealed that there were no significant differences $(F \mathrm{~s}<1.0)$ among the startle amplitudes of no-shock control rats receiving the initial startle stimulus $30 \mathrm{sec}$ versus $90 \mathrm{sec}$ after exposure to the startle chambers. Therefore, data from these rats were combined to produce a single no-shock control group.

Mean startle response amplitudes averaged across blocks of four stimulus presentations for the three groups are shown in Figure 2. Whereas the delivery of shock $60 \mathrm{sec}$ after exposure to the novel context potentiated the startle response, no such effect occurred in the immediate-shock condition. Statistical analysis revealed that rats in the delayed shock group showed significantly higher startle responses than did those in the no-shock group $[F(1,36)=12.0, p<.005]$ or immediate-shock condition $[F(1,36)=13.4, p<.001]$. There was no significant difference between the startle amplitudes of rats not receiving shock and rats given an immediate shock $(F<1.0)$. There was a significant overall linear trend $[F(1,36)=27.1, p<.0001]$, indicating that startle amplitude progressively increased across presentations. However, the contrasts testing for the interaction between linear trend and group differences were not significant $(F \mathrm{~s}<1.0)$. From inspection of the figure, this failure to detect evidence for significant interactions suggests that rats shocked after a delay showed a persistently greater startle response than did no-shock rats, whereas rats in the immediate condition showed increased startle amplitudes across stimulus presentations, but in a manner that was indistinguishable from startle amplitudes for the control group.

\section{Discussion}

These findings are consistent with the proposal of the PDR model that painful stimuli do not unconditionally elicit a fear state (Bolles \& Fanselow, 1980). The failure of immediate shock to potentiate the amplitude of the startle response (Young, Rabchenuk, Landeira-Fernandez, Helmstetter, \& Leaton, 1990) suggests that shock itself does not activate the fear taken to subserve startle potentiation. This suggestion is inconsistent with the results of two experiments on shock-potentiated startle reported by Davis (1989). To test whether shock-potentiated startle was due to fear conditioning of contextual cues, Davis presented rats with 40 startle stimuli under one lighting condition, which terminated with the delivery of shock. Following shock, the rats were presented with a further 40 startle stimuli, under either the same or different lighting conditions from those during the delivery of the shock. Davis found that postshock startle amplitudes were augmented relative to preshock startle, but that there was no difference between groups as a function of the change in contextual lighting conditions. In a further experiment, Davis arranged that rats received a training session which consisted of: (1) 40 startle stimuli, followed by a series of 10 shocks and then a further 40 startle stimuli, or (2) 80 startle stimuli without shock. Both groups were tested across 80 startle stimuli $24 \mathrm{~h}$ later in the same context. Davis found that these groups did not differ significantly on startle amplitudes across the test session. On the basis of these tests, he concluded that the shock enhanced startle responding by directly eliciting fear rather than by conditioning fear to the associated contextual cues. 
However, the failure to detect any differences between the startle responses of shocked rats tested under the same or different lighting conditions could reflect a failure of conditioning of these cues by shock. For example, it is possible that the lighting cues were overshadowed by the tactile and olfactory CSs that were also present on test. In other words, in the initial experiment, Davis (1989) did not provide any independent evidence regarding the associability of the particular lighting cues with shock. Moreover, in the second experiment, the failure to detect differences between the startle responses of nonshocked and shocked rats involved a procedure in which rats remained in the shocked context for $20 \mathrm{~min}$ in the absence of shock. That exposure could have extinguished the fear conditioned to that context, thereby undermining the associative basis for a difference on the test conducted $24 \mathrm{~h}$ later.

It is important to note that there are several differences between our procedure and that used by Davis (1989), most notably in the number and intensity of shocks delivered. A future investigation of shock-sensitized startle versus associatively mediated potentiated startle could deliver either one or multiple shocks in one context and then immediately test for startle either in that or in a different context.

\section{EXPERIMENT 3}

Fanselow (1986a, 1990) has argued that the differences in levels of freezing resulting from delayed versus immediate shock are due to variations in what has been learned about contextual cues. Specifically, rats shocked after a delay freeze as a result of associating shock with a unitized representation of the contextual cues. In contrast, rats shocked immediately do not freeze, because of insufficient time to construct the unitized representation taken to be critical for the association between shock and contextual cues, even if they have been preexposed to the contextual cues. Conditioned freezing can be increased at very short delays, however, in rats that have already constructed this representation across preexposures to that context.

An implication of this reasoning is that activation of the unitized memory of the contextual cues in advance of shock exposure will alleviate the immediate-shock freezing deficit. In Experiment 3, we tested this implication by exposing rats to a context in advance of immediate shock delivery upon reexposure to that context. The unitized representation set up by the initial context exposure should be available when shock occurs upon reexposure, thereby mediating the associative impact of shock upon the freezing response.

Two training contexts (E1 and E2) and a control context (E0) were used to test this hypothesis. We presented rats with two immediate-shock sessions, one in each of the training contexts. The design was fully counterbalanced, but for ease of explanation, we will describe one permutation. We placed rats in Group Same into E1 for $30 \mathrm{sec}$, removed them and immediately replaced them into E1, delivered immediate shock, and left the rats in that context for a further $60 \mathrm{sec}$. Four hours later the procedure was repeated, but E2 was used instead of E1. The rats in Group Different were treated similarly, except that immediate shock in either E1 or E2 was delivered after exposure to the other context. In other words, these rats were exposed to $\mathrm{E} 1$ and then given a shocked exposure to E2. Later, these rats were exposed to E2 and given a shocked exposure to E1. Rats in Group Control also received immediate shock in both $\mathrm{E} 1$ and $\mathrm{E} 2$, but preshock exposure was always in E0. This arrangement ensured that all rats experienced equivalent immediateshock experience in both E1 and E2. Groups Same and Different also received equivalent overall experience of E1 and E2. These groups differed in that Group Same was shocked in the context that had just been experienced, whereas Group Different received shock in a different context from that just experienced. We also preexposed all rats to $E 1$ and $E 2$ for 2 min on four occasions in order to enhance the discriminability of these contexts. Thus, if conditioned freezing is enhanced whenever a unitized representation of contextual cues is present at the time of shock delivery, then rats in Group Same should display more freezing than rats in the other groups.

\section{Method}

Subjects. Twenty-four experimentally naive male Wistar SPF rats $(300-400 \mathrm{~g})$ were obtained from the same source and kept under the conditions described in Experiment 1.

Apparatus. The contexts consisted of two chambers $(38 \times$ $30 \times 23 \mathrm{~cm})$. The front wall and hinged lids of each chamber were constructed of Perspex. The side- and rear walls were made out of wood and painted with $2-\mathrm{cm}$-wide black and white stripes. The stripes were vertical in one chamber and horizontal in the other. Extractor fans were mounted on the rear wall of each chamber to expel odors and provide a masking noise. The floors consisted of stainless steel rods, $2 \mathrm{~mm}$ in diameter, spaced $13 \mathrm{~mm}$ apart center to center. The floors were located $8 \mathrm{~cm}$ above a tray filled with wood shavings. The floor of one chamber (E1) was wiped with acetic acid $(0.5 \mathrm{ml}$ per $100 \mathrm{ml}$ of water) and the floor of the other chamber (E2) was wiped with almond essence $(1.0 \mathrm{ml}$ per $100 \mathrm{ml}$ of water) before a rat was placed into the chamber. A Perspex cylinder ( $36 \mathrm{~cm}$ high, $24 \mathrm{~cm}$ diameter) with a copper floor served as E0 and was wiped with tap water before subject placements. Scrambled shock could be delivered to the floors of E1 and E2 by separate Grason-Stadler (Type E1064GS) shock generators located in another room.

Procedure. We allocated rats randomly to one of three groups designated same, different, or control. All subjects were preexposed to both E1 and E2 (counterbalanced within groups) for 2 min on each of 4 consecutive days. At least 10 min intervened between context exposures on each day.

On Day 5, the rats received a $1-\mathrm{sec}, 0.75-\mathrm{mA}$ grid shock immediately upon placement into $\mathrm{E} 1$ and $\mathrm{E} 2$. Exposures to $\mathrm{E} 1$ and to $\mathrm{E} 2$ were separated by $4 \mathrm{~h}$. The order of exposure to $\mathrm{E} 1$ and to $\mathrm{E} 2$ was counterbalanced across subjects within each group. The chambers designated as E1 and E2 were also counterbalanced within each group. Groups differed in terms of the context in which immediate shock was delivered. Specifically, rats in Group Same were exposed to E1 for $30 \mathrm{sec}$, briefly removed, and returned to E1, where they received an immediate shock. The rats remained in E1 for $60 \mathrm{sec}$ postshock. Four hours later, these rats were exposed to E2 for $30 \mathrm{sec}$, briefly removed, and returned to E2, where they re- 
ceived an immediate shock. These rats again remained in E2 for $60 \mathrm{sec}$. The rats in Group Different were exposed to E2, removed, and placed in EI, where they received an immediate shock. Four hours later, these rats were exposed to E1, removed, and placed in E2, where they received an immediate shock. Finally, the rats in Group Control were treated similarly except that exposure to E0 occurred in advance of immediate shock treatment in E1 and E2. Freezing was scored every second across the $60 \mathrm{sec}$ in which the rats remained in the shocked context.

On Days 6 and 7, we tested the rats. Each test was 2 min in duration, and shock was not presented. On each of these days, the rats were exposed to E1 and to E2 with $4 \mathrm{~h}$ between exposures. The order in which rats were exposed to E1 and to E2 was counterbalanced within each group. Freezing was scored every alternate second on each test exposure. A contrast testing procedure (Hays, 1972) was used to analyze the results, with $\alpha=.05$.

\section{Results}

Mean time spent freezing by rats in each of the groups is shown in Figure 3. The left panel shows the freezing that occurred after the initial and second shocked exposures on Day 5, and the right panel shows the freezing on Days 6 and 7 averaged across the two shocked contexts. The figure suggests that rats preexposed immediately before a shocked exposure (Groups Same and Different) displayed more freezing than did rats not receiving that preexposure (Group Control). Moreover, unless obscured by ceiling effects, rats shocked in the context to which they had just been preexposed (Group Same) showed more freezing than did rats shocked in a different context from that which they had just experienced (Group Different).
These observations were confirmed by the statistical analysis, which revealed that rats in Groups Same and Different showed significantly more freezing than did rats in Group Control $[F(1,21)=17.9, p<.0005]$ and that Group Same showed significantly more freezing than did Group Different $[F(1,21)=7.2, p<.05]$. Repeat contrasts showed that there was significantly more freezing in the postshock period of the second training session than in the first session $[F(1,21)=81.2, p<$ $.0001]$, and more freezing across the extinction trials (averaged across the counterbalanced contexts) of Day 6 than of Day $7[F(1,21)=119.1, p<.0001]$. Appropriate group $\times$ repeat interactions showed that there was significantly more freezing in Group Same than in Group Different in both the acquisition $[F(1,21)=4.8, p<.05]$ and extinction $[F(1,21)=7.3, p<.05)$ phases. The comparable levels of postshock freezing observed between Groups Same and Different on the second exposure of Day 5 can be attributed to ceiling effects resulting from the use of two training sessions. This reasoning is supported by the different pattern of freezing observed in these groups across the extinction sessions (Days 6 and 7).

\section{Discussion}

Rats receiving preexposure to the same context in which shock was later delivered during conditioning (Group Same) showed more freezing than did rats experiencing a change in contexts across preexposure and conditioning phases (Groups Different and Control). This result is consistent with Fanselow's (1990) expla-

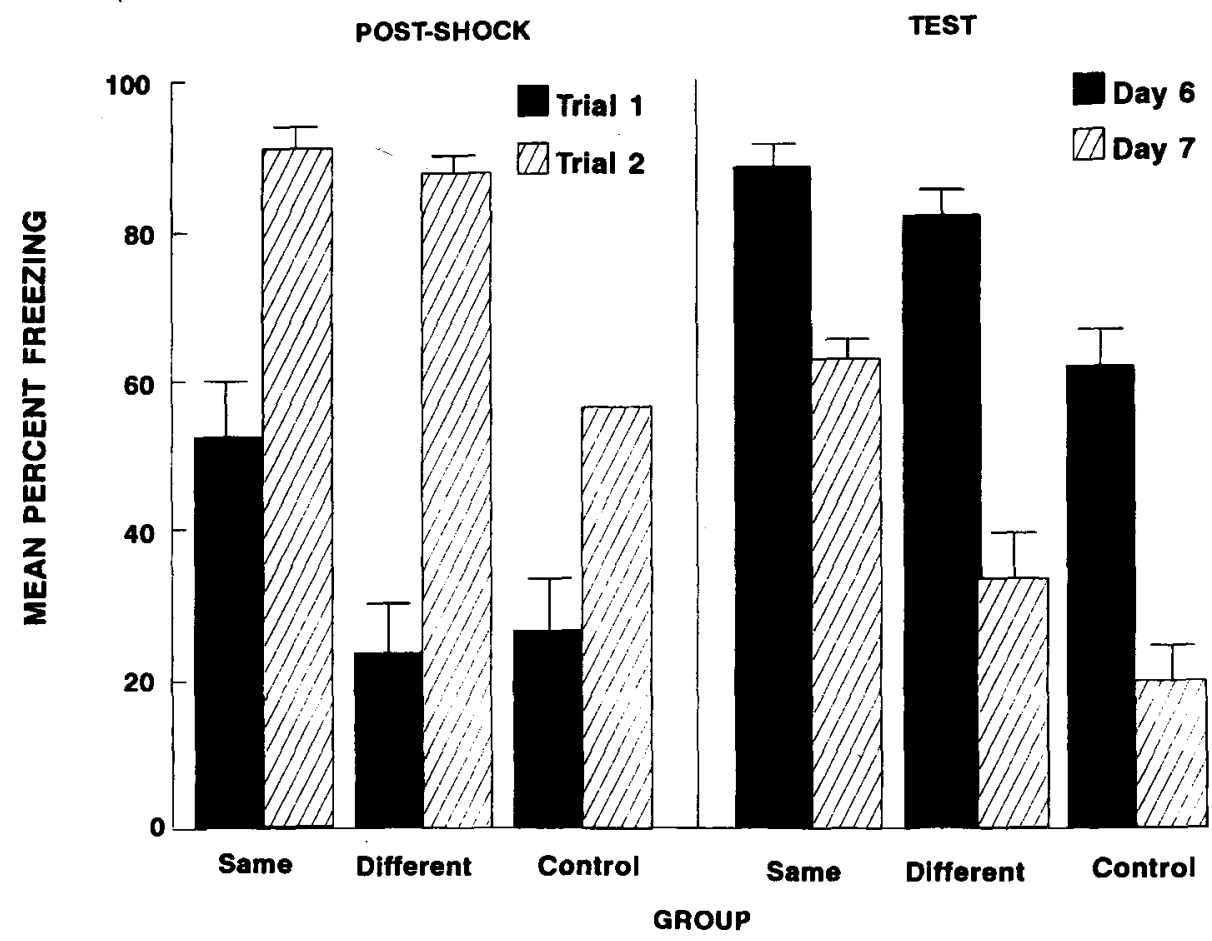

Figure 3. Mean percent freezing (postshock) across the two conditioning trials (left panel) and across tests (right panel) in Experiment 3. Rats in Group Same received immediate shock in the just experienced context, whereas rats in Groups Different and Control were shocked in a context that differed from the context just experienced. T-bars represent SEMs. 
nation of the immediate-shock freezing deficit. According to this account, the freezing deficit is an associative failure caused by inadequate retrieval or processing of contextual cues at the moment of shock delivery. In this regard, preexposure, removal, and placement back into the same context in the present experiment served to reactivate the appropriate unitized contextual memory prior to the presentation of immediate shock, thereby attenuating the typical deficit in conditioned freezing. Moreover, a change in context across preexposure and conditioning phases should have precluded the processing of shock with the appropriate contextual memory, thereby producing an immediate-shock freezing deficit.

\section{GENERAL DISCUSSION}

These experiments demonstrate that the co-occurrence of shock and exposure to a novel context produces deficits not only in freezing but also in other indexes of fear conditioning - notably, passive avoidance and potentiation of startle. Such deficits appear to challenge the manner in which models such as SOP (Wagner, 1981) or AESOP (Wagner \& Brandon, 1989) conceptualize the processes by which links between representations of CSs and a shock US result in the performance of conditioned responding. Specifically, these models propose that the node acted upon by a shock US undergoes changes in the pattern of activity among its elements, such that some proportion of elements are activated from a state of inactivity (I) to a state of primary activity (A1), from which they decay to a secondary state (A2) before returning to I. Importantly (1) the primary and secondary states of activation are each accorded behavioral controlling properties, and (2) CSs paired with a shock US are held to provoke the behaviors characteristic of that US when processed in A2.

From this view, evidence for conditioned freezing indicates that freezing constitutes a component of the A2 reaction to the shock US. Similarly, evidence for passive avoidance and potentiated startle implies that the conditioned fear taken to mediate these behaviors is a property of the shock US when processed in A2. However, this evidence was obtained from rats shocked after a delay, but not from rats shocked immediately upon exposure to the novel environment. Moreover, immediate shock did not result in any detectable changes in either freezing or startle responding, findings inconsistent with the view that freezing and/or fear are provoked by A2 processing of the shock US. Of course, it is possible that the cooccurrence of shock with exposure to a novel context disrupts the processing accorded the shock US. For example, A1 processing of the novel contextual cues may have diminshed that afforded the shock US, thus undermining the A2 processing held to be crucial for the fear UR to the shock US. Alternatively, activation of a nociceptive intensity detector by novel contextual cues (Bardo \& Hughes, 1979; Foo \& Westbrook, 1991) may have reduced the functional intensity of the shock US, thereby impairing the capacity of the shock to provoke a fear UR.

Rather than a UR to a shock US, fear is a response to CSs paired with shock according to the PDR model (Bolles \& Fanselow, 1980; Fanselow, 1990). Thus, fear will be present under circumstances that favor the conditioning of those CSs by that US, such as when shock is presented some time after exposure to a novel context. In contrast, fear will not be observed when circumstances do not provide for that conditioning but which do involve the presentation of shock, such as when shock co-occurs with exposure to that context. Fanselow (1986a, 1990) has argued that the differences between immediate and delayed shock with respect to fear conditioning are a result of the insufficient processing of the context into a unitized CS among immediately shocked rats. Moreover, the time taken to retrieve this unitized CS from LTM will constrain the associability of contextual cues among rats preexposed to the conditioning context. An implication of these arguments is that the presence of a unitized CS in STM at the time of shock will alleviate the deficit in fear conditioning resulting from immediate shock. The results of Experiment 3 were consistent with this reasoning, demonstrating that rats exposed to the shocked context prior to immediate shock display more conditioned freezing than rats processing an alternative context. Since preexposure to the to-be-conditioned context fails to alleviate the freezing deficit with immediate shock due to insufficient retrieval time, we argue that the critical factor underlying the enhanced freezing observed in Group Same is that the representation of the context was still available in STM when immediate shock was delivered, and not simply the retrieval of the representation established during preexposure.

In summary, in the present experiments delayed shock was contrasted with immediate shock, showing that the former but not the latter results in evidence for conditioned fear. The failure to detect evidence for postshock freezing or potentiated startle was taken to be consistent with the view that fear is a response to CSs paired with shock rather than a reaction to shock itself. Finally, preexposure to the shocked context alleviated the deficit in freezing resulting from immediate shock, a result consistent with the hypothesis that this deficit results from insufficient processing of the context into a unitized CS.

\section{REFERENCES}

Bardo, M. T., \& Hughes, R. W. (1979). Exposure to a non-functional hotplate as a factor in the assessment of morphine-induced analgesia and analgesic tolerance. Pharmacology, Biochemistry \& Behavior, 10, 481-485.

BlanChaRd, R. J., \& BlANChARD, D. C. (1969). Crouching as an index of fear. Journal of Comparative \& Physiological Psychology, 67, 370-375.

Blanchard, R. J., Fukunaga, K. K., \& Blanchard, D. C. (1976). Environmental control of defensive reactions to footshock. Bulletin of the Psychonomic Society, 8, 129-130. 
Bolles, R. C., \& Fanselow, M. S. (1980). A perceptual-defensiverecuperative model of fear and pain. Behavioral \& Brain Sciences, 3, 291-301

Brown, J. S., Kalish, H. I., \& Farber, I. E. (1951). Conditioned fear as revealed by the startle response to an auditory stimulus. Journal of Experimental Psychology, 41, 317-327.

DAvis, M. (1989). Sensitization of the acoustic startle reflex by footshock. Behavioral Neuroscience, 103, 495-503.

Davis, M., \& Astrachan, D. I. (1978). Conditioned fear and startle magnitude: Effects of different footshock or backshock intensities used in training. Journal of Experimental Psychology: Animal Behavior Processes, 4, 95-103.

FANSELOW, M. S. (1980). Conditional and unconditional components of post-shock freezing. Pavlovian Journal of Biological Science, $15,177-182$.

FANSELOW, M. S. (1982). The postshock activity burst. Animal Learning \& Behavior, 10, 448-454.

Fanselow, M. S. (1984). What is conditioned fear? Trends in Neuroscience, $7,460-462$.

FANSELOW, M. S. (1986a). Associative vs topographical accounts of the immediate shock-freezing deficit in rats: Implications for the response selection rules governing species-specific defensive reactions. Learning \& Motivation, 17, 16-39.

FANSELOW, M. S. (1986b). Conditioned fear-induced opiate analgesia: A competing motivational state theory of stress-analgesia. In D. D. Kelly (Ed.), Stress induced analgesia (Annals of the New York Academy of Sciences, Vol. 467, pp. 40-54).

FANSELOW, M. S. (1990). Factors governing one-trial contextual conditioning. Animal Learning \& Behavior, 18, 264-270.

FoO, H., \& WestBRook, R. F. (1991). Naloxone-induced hypoalgesia: Effects of heat, cold and novelty. Quarterly Journal of Experimental Psychology, 43B, 137-156.

HAYS, W. L. (1972). Statistics for the social sciences. New York: Holt, Rinehart \& Winston.

Kiernan, M. J., \& WeSTbRooK, R. F. (1993). Effects of exposure to a to-be-shocked environment upon the rat's freezing response: Ev- idence for facilitation, latent inhibition and perceptual learning. Quarterly Journal of Experimental Psychology, 46B, 271-288.

Leaton, R. N., \& Borszcz, G. S. (1985). Potentiated startle: Its relation to freezing and shock intensity in rats. Journal of Experimental Psychology: Animal Behavior Processes, 11, 421-428.

LeitNer, D. S., \& Rosenberger, M. C. (1983). A simple and inexpensive startle transducer with high output. Behavior Research Methods \& Instrumentation, 15, 508-510.

MiLlER, R. G. (1966). Simultaneous statistical inference. New York: McGraw Hill.

WAGNER, A. R. (1981). SOP: A model of automatic memory processing in animal behavior. In N. E. Spear \& R. R. Miller (Eds.), Information processing in animals: Memory mechanisms (pp. 5-47). Hillsdale, NJ: Erlbaum.

WAGNER, A. R., \& BRANDON, S. E. (1989). Evolution of a structured connectionist model of Pavlovian conditioning (AESOP). In S. B. Klein \& R. R. Mowrer (Eds.), Contemporary learning theories. Pavlovian conditioning and the status of traditional learning theory (pp. 149-190). Hillsdale, NJ: Erlbaum.

WESTBROOK, R. F., GoOD, A. J., \& KiERNAN, M. J. (in press). Effects of the interval between exposure to a novel environment and the occurrence of shock upon the freezing responses of rats tested in that or in a second environment. Quarterly Journal of Experimental Psychology.

Westbrook, R. F., Greeley, J. D., Nabke, C. P., \& Swinbourne, A. L. (1991). Aversive conditioning in the rat: Effects of a benzodiazepine and of an opioid agonist and antagonist on conditioned hypoalgesia and fear. Journal of Experimental Psychology: Animal Behavior Processes, 17, 219-230.

Young, B. J., Rabchenuk, S., Landeira-Fernandez, J., HelmstetTER, F. J., \& LEATON, R. N. (1990, March). Delayed but not immediate footshock potentiates the acoustic startle reflex and enhances freezing in rats. Paper presented at the meeting of the Eastern Psychology Association, Philadelphia.

(Manuscript received August 25, 1993; revision accepted for publication April 3, 1994.) 